\title{
High prevalence of Vitamin D deficiency during pregnancy: A social health problem in India
}

\author{
K. V. S. Hari Kumar, Sandeep Kumar, A. S. Dhillon ${ }^{1}$, Sudhir Mansingh ${ }^{1}$, Sandeep Sood ${ }^{1}$ \\ Departments of Endocrinology and ${ }^{1}$ Gynecology, Command Hospital, Chandimandir, Panchkula, Haryana, India
}

\section{A B S T R A C T}

Background:Vitamin D deficiency (VDD) is an important public health problem and is implicated as a risk factor for glucose intolerance during pregnancy. We studied the prevalence of VDD in patients with gestational diabetes mellitus (GDM) and type 2 diabetes mellitus (T2DM). Materials and Methods: All GDM and T2DM patients evaluated between October and December 2014 were included in this cross-sectional, observational study. Patients with the use of vitamin D, glucocorticoids, and secondary diabetes were excluded. We diagnosedVDD as a serum 25-hydroxyvitamin D (25OHD) less than $30 \mathrm{ng} / \mathrm{ml}$ and GDM based on the World Health Organization (WHO) criteria. The data were compared with 10 gestational, age-matched controls with normal glucose tolerance (NGT).Appropriate statistical methods were used for comparison between the three groups. Results: The study participants (37 GDM, I3 T2DM, and I0 NGT) had a median $\left(25^{\text {th }}-75^{\text {th }}\right.$ interquartile) age of $26(24.3,30)$ years, gestational age of $24.5(21,27)$ weeks, and $250 H D$ of I0.5 (8.I, I4.8) ng/ml. VDD was seen in 35 GDM, I 2 T2DM, and eight patients with NGT $(P=0$. 9637). The median 25OHD levels were comparable between the three groups $(10,10.6$, and $13.95 ; P=0$. I 192). Univariate analysis did not show higher odds of GDM or T2DM in patients with VDD $(P=0.1903)$. Conclusion: Our data showed that the prevalence of VDD is high during pregnancy, irrespective of the glucose intolerance. Large scale population studies are required to determine the association between the VDD and GDM.

Key words: Gestational diabetes, India, pregnancy, prevalence, type 2 diabetes, vitamin D

\section{INTRODUCTION}

Vitamin D deficiency (VDD) is the widely reported nutritional deficiency affecting the global population. ${ }^{[1]}$ The traditional role of vitamin $\mathrm{D}$ is in maintaining the musculoskeletal health and mineralization of the bone. The identification of the vitamin $\mathrm{D}$ receptors leads to an expanded role of the vitamin D beyond the skeleton. ${ }^{[2]}$ Vitamin D is involved in the cell proliferation and differentiation, and its deficiency has been implicated as a causative factor in many metabolic, autoimmune, and neoplastic disorders. Vitamin D has an established role in the glycemic

\begin{tabular}{|l|l|}
\hline \multicolumn{2}{|c|}{ Access this article online } \\
\hline Quick Response Code: & Website: \\
\hline & www.josh.net \\
\hline & \\
\hline & \\
\hline
\end{tabular}

metabolism, both in the insulin secretion and its cellular action. ${ }^{[3]}$ During the last decade, there is an exponential rise in the research pertaining to vitamin $\mathrm{D}$ in glucose intolerance. Epidemiological studies suggest a higher risk of type 2 diabetes mellitus (T2DM) in patients with VDD. ${ }^{[4]}$ Few researchers have also explored the therapeutic role of vitamin $\mathrm{D}$ in the management of T2DM. ${ }^{[5]}$

Gestational diabetes mellitus (GDM) is seen in about $20 \%$ of the total pregnancies in our country. ${ }^{[6]}$ GDM is a harbinger for the future T2DM with an approximate conversion rate of $5 \%$ per year. ${ }^{[7]}$ Though, enough data

\begin{abstract}
This is an open access article distributed under the terms of the Creative Commons Attribution-NonCommercial-ShareAlike 3.0 License, which allows others to remix, tweak, and build upon the work non-commercially, as long as the author is credited and the new creations are licensed under the identical terms.
\end{abstract}

For reprints contact: reprints@medknow.com

How to cite this article: Kumar KH, Kumar S, Dhillon AS, Mansingh S, Sood S. High prevalence of Vitamin D deficiency during pregnancy: A social health problem in India. J Soc Health Diabetes 2016;4:36-40.

Corresponding Author: Dr. K. V. S. Hari Kumar, Departments of Endocrinology and Gynecology, Command Hospital, Chandimandir, Panchkula - 134 107, Haryana, India. E-mail: hariendo@rediffmail.com 
exist to support the association between VDD and T2DM, the same has been lacking in GDM ${ }^{[8]}$ Pregnancy offers an ideal opportunity to screen the patients at high risk for VDD. The identification of VDD helps in proper therapy, thereby reducing the risk of future GDM and T2DM. This intervention also has a public health importance, because VDD is a modifiable risk factor for GDM..$^{[9]}$ There are sparse data from India regarding the prevalence of VDD in patients with T2DM and GDM. ${ }^{[10]}$ Hence, we conducted this study to assess the prevalence of VDD in patients with T2DM and GDM.

\section{MAterials ANd Methods}

\section{Study population}

This was a cross-sectional, observational study conducted at a tertiary care hospital located in India (latitude: $\left.30^{\circ} 74^{\prime}\right)$. The participants were recruited from the antenatal clinic of our hospital, with a referral to the endocrinology department for management of diabetes. Serial patients with a diagnosis of GDM and T2DM seen between October and December 2014 were included in the study. The detail of the study procedure has been shown in the Figure 1. All patients with a diagnosis of T2DM (received a prescription for an oral hypoglycemic agent or insulin) for at least 1 year duration were included. We excluded patients with any major illness, surgery, or diabetic ketoacidosis in last 6 months; secondary diabetes; and the use of glucocorticoids or vitamin D preparations. Control population was derived from the patients attending the antenatal clinic and is free from

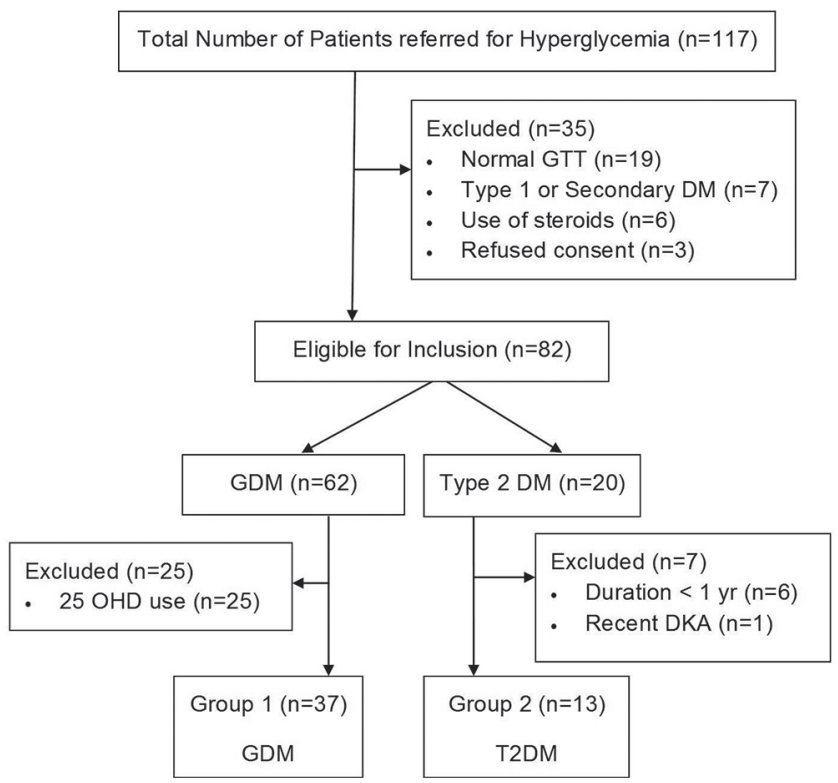

Figure 1: Flow diagram of the study. GTT = Glucose tolerance test, T2DM = Type 2 diabetes mellitus, $\mathrm{OHD}=$ Hydroxyvitamin D, DKA = Diabetic ketoacidosis, GDM = Gestational diabetes mellitus any systemic illness with normal glucose tolerance (NGT). We had a predetermined objective of including 10 NGT patients as controls for the comparison. The patients were divided into three groups for the analysis as per the underlying diagnosis: Group 1 (GDM), Group 2 (T2DM), and Group 3 (NGT).

\section{Study measures}

Clinical data were collected from all the participants, including demographic details like age, gestational age, parity, family history of diabetes, and duration of T2DM (in Group 2 only). Our hospital is a service hospital with a wide referral area and the dependent clientele hails from different domiciles of the India. Hence, we did not collect the dietary patterns which may influence vitamin D. Details of the therapy prescribed was noted, including the diet control alone, diet plus metformin, or use of insulin. The local ethics committee approved the study protocol and all patients provided written informed consent.

\section{Definitions}

All the participants except group 2 (T2DM) were subjected to the $75 \mathrm{~g}, 2$-hour glucose tolerance test. We used recommendations of the American Diabetes Association (ADA) for the diagnosis of GDM. ${ }^{[1]}$ Fasting and post meal blood glucose values were obtained from the T2DM patients. 25-hydroxyvitamin D (25OHD) was measured by chemiluminescence method and coefficient of variation of the test is less than $10 \%$. The assessment of $25 \mathrm{OHD}$ was done based on the recommendations of the Endocrine Society into sufficiency $(>30 \mathrm{ng} / \mathrm{ml})$ and deficiency or insufficiency $(<30 \mathrm{ng} / \mathrm{ml}) \cdot{ }^{[12]}$ The categories of insufficiency and deficiency were not assessed separately due to the small sample size. There are no Indian guidelines defining the normal 25OHD levels, and the recently published guidelines from the Institute of Medicine (IOM) have been criticized widely in the literature. ${ }^{[13]}$ Hence, in our study, we used the guidelines issued by the Endocrine Society. All the participants with hypovitaminosis $\mathrm{D}$ were given weekly vitamin D oral sachet of 60,000 units for 12 weeks, followed by once a month.

\section{Statistical analysis}

Data are presented as median (interquartile ranges) and descriptive statistics were used for data analysis. We used median as a measure of central tendency instead of mean due to small sample size and the skewed distribution. Kruskal-Wallis test was used to compare between the groups of the study. To identify the associations with vitamin $\mathrm{D}$, univariate logistic regression analysis was conducted with VDD (yes/no) as a dependent variable and others as independent continuous variables. The results 
are expressed as odds ratio (OR) and 95\% confidence intervals (CIs). Spearman's correlation was used to study the association between 25OHD and other clinical parameters. A two-tailed $P$ - value of less than 0.05 was considered significant for all the tests. The statistical analysis and graph generation was done using the Graphpad Prism Software, Version 6 (Graphpad Software, San Diego, CA, USA).

\section{RESULTS}

The study participants (37 GDM, 13 T2DM, 10 NGT) had a median $\left(25^{\text {th }}-75^{\text {th }}\right.$ interquartile range $)$ age of $26(24.3,30)$ years, gestational age of $24.5(21,27)$ weeks, and $25 \mathrm{OHD}$ of $10.5(8.1,14.8) \mathrm{ng} / \mathrm{ml}$. VDD was seen in 35 GDM, 12 T2DM, and eight patients with NGT $(P=0.9637)$. In the entire study population, only five out of 60 (8.3\%) patients had normal 25OHD levels. The median 25OHD levels were comparable between the three groups $(10,10.6$, and 13.95; $P=0.1192)$. The baseline parameters and detailed comparison between the three groups is given in Table 1 . Briefly, the results show that the patients with T2DM were older in comparison to other groups and were referred to the endocrinology department at an early gestational age. Positive family history is observed more frequently in patients with any glucose intolerance in comparison to control population.

The majority of the participants required metformin along with the dietary intervention for the control of blood glucose. Three patients with GDM were treated with dietary control alone, 22 patients required metformin and the remaining 12 were prescribed with insulin. Insulin was used in eight patients of T2DM group and the remaining five used metformin. Logistic regression models were used to quantify the association between vitamin $\mathrm{D}$ levels and the risk of diabetes. The OR and 95\% CI of finding a VDD did not differ with the use of insulin (OR: 1.3571, CI: 0.1148-16.0476), parity (OR: 0.5217, CI: 0.0442-6.154), and the diagnosis of GDM/T2DM (OR: 0.6857, CI:
0.0569-8.2576, $P=0.1903$ ) as shown in Figure 2. We did not adjust the regression model for the confounders due to the relatively small sample size. Spearman's test did not show any correlation between vitamin D level and the gestational age, parity, blood glucose, and the use of insulin (data not shown).

\section{DISCUSSION}

Our study showed that very few patients (five out of 60) have normal $25 \mathrm{OHD}$ levels in the pregnancy. The data is same across the spectrum of glucose intolerance and was not different between the T2DM, GDM, and the control population. The population prevalence of VDD is approximately $90 \%$ in our country. ${ }^{[14]}$ Previous reports from other nations also reported VDD in more than $80 \%$ of their population. ${ }^{[1,15]}$ Our results failed to show higher odds of finding glucose intolerance in patients with VDD. This result is similar to the previously published report on the subject from our country. ${ }^{[16]}$ Farrant et al., reported the prevalence of hypovitaminosis D in $97 \%$ of their patients with no increased risk of GDM in patients with VDD. ${ }^{[16]}$ The majority of researchers, barring from

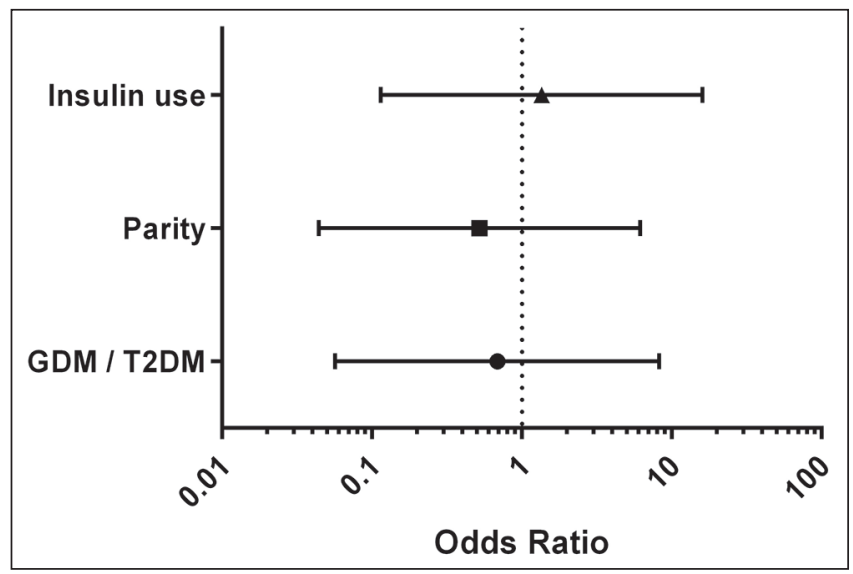

Figure 2: Odds ratio of insulin use, parity, and diabetes with vitamin D deficiency

\begin{tabular}{|c|c|c|c|c|c|}
\hline Parameter & Units & $\begin{array}{c}\text { Group } 1 \text { (GDM) } \\
n=37\end{array}$ & $\begin{array}{c}\text { Group } 2 \text { (T2DM) } \\
n=13\end{array}$ & $\begin{array}{c}\text { Group } 3 \text { (NGT) } \\
n=10\end{array}$ & $P$-value \\
\hline Age & Years & $26(24.5,28)$ & $30(25.5,33)$ & $24.5(24,30)$ & 0.0295 \\
\hline Body weight & $\mathrm{kg}$ & $67(64,71.8)$ & $63.5(61.8,78.5)$ & $66.5(64.9,70)$ & 0.6857 \\
\hline Parity & Number & $1(1,2)$ & $2(1,2.5)$ & $1.5(1,2.25)$ & 0.4339 \\
\hline Family history of (h/o) DM & Number & 18 & 8 & 1 & 0.0370 \\
\hline $\begin{array}{l}\text { Gestational age } \\
75 \mathrm{~g} \text { GTT }\end{array}$ & Weeks & $26(22,30.5)$ & $21(17,26)$ & $24(22,25)$ & 0.0392 \\
\hline $\mathrm{Oh}$ & $\mathrm{mg} / \mathrm{dl}$ & $99(95,105)$ & $104^{*}(96.5,113.5)$ & $85.5(76.8,89.5)$ & 0.0002 \\
\hline $1 \mathrm{~h}$ & $\mathrm{mg} / \mathrm{dl}$ & $170(158,191)$ & - & $112(110,129.8)$ & $<0.0001$ \\
\hline $2 \mathrm{~h}$ & $\mathrm{mg} / \mathrm{dl}$ & $142(134,155)$ & $150 *(138,174)$ & $103.5(91,110)$ & $<0.0001$ \\
\hline 25-hydroxyvitamin D & $\mathrm{ng} / \mathrm{ml}$ & $10(8.1,13.2)$ & $10.6(8.8,14.9)$ & $13.9(9.2,20.6)$ & 0.1192 \\
\hline
\end{tabular}

Median (95\% confidence interval (CI)). GDM = Gestational diabetes mellitus; T2DM = Type 2 diabetes mellitus, NGT = Normal glucose tolerance, GTT = Glucose tolerance test, *Fasting and post lunch blood glucose values 
the United States of America (USA) has observed low 25OHD levels during pregnancy and an enhanced risk of developing GDM. ${ }^{[17]}$ The USA has identified VDD as an important public health problem and managed the same by fortification of the food products with vitamin D. Hence, research exploring the link between VDD and GDM did not find any association from the USA.

The widespread prevalence of VDD provoked the investigators to suggest routine screening for VDD during pregnancy. ${ }^{[18]}$ Few authors from India have suggested that vitamin D replacement helps in reducing the risk of maternal comorbidities and also improves neonatal outcomes. ${ }^{[10]} \mathrm{A}$ recently published meta-analysis on the subject showed that VDD in pregnancy had higher odds (OR 1.61) of developing the GDM. ${ }^{[19]}$ The observed difference in our study could be due to the small sample size and difference of $25 \mathrm{OHD}$ levels in normal population. The confounding factors to be studied during assessment for VDD in pregnancy include skin pigmentation, race, dietary pattern, sun exposure, and physical activity. We did not do the multivariate logistic regression analysis to eliminate this confounder effect. Few reports have suggested that VDD is more marked in the primigravida when compared with multigravida and our data does not show similar trends. ${ }^{[20]}$

VDD is a potentially modifiable risk factor for many metabolic disorders and optimum levels of vitamin are essential for good pregnancy outcomes. Vitamin D supplementation improves the insulin sensitivity and glucose tolerance during pregnancy, and a recent report suggests a dose-response relationship between these variables. ${ }^{[21]}$ The strengths of our study include the typical patient profile seen at any tertiary care level hospital in India. The patients are derived from a mixed population covering the northern and southern states of India, and thus may be applied to the entire country. The limitations of our study include small sample size, inability to nullify the confounder effect, and the cross-sectional design of the study. Prospective studies with large number of patients are required to further guide the clinicians about optimum vitamin $\mathrm{D}$ replacement strategies in pregnancy. Family physicians play a vital role in the maternal care and our manuscript helps in educating them about the prevalence of VDD in pregnancy. This also prompts the practitioners to identify and treat VDD during pregnancy, thereby reducing the perinatal morbidity.

\section{CONCLUSION}

To conclude, our data confirms the high prevalence of VDD in pregnancy irrespective of the glycemic intolerance status. Our study has certain public health implications in the form of formulating guidelines regarding the diagnosis and management of VDD in pregnancy. Our study gives more impetus to the researchers and policy makers to improve the vitamin $\mathrm{D}$ status during pregnancy in order to reduce the associated maternal and neonatal morbidity.

\section{Acknowledgements}

The authors sincerely acknowledge the help rendered by $\mathrm{Nb}$ / Sub JBS Yadava, Department of Endocrinology and all the laboratory staff in conduct of the study.

Financial support and sponsorship

Nil.

Conflicts of interest

There are no conflicts of interest.

\section{REFERENCES}

1. Palacios C, Gonzalez L. Is vitamin D deficiency a major global public health problem? J Steroid Biochem Mol Biol 2014; 144:138-45

2. Wacker M, Holick MF. Vitamin D - effects on skeletal and extraskeletal health and the need for supplementation. Nutrients 2013;5:111-48.

3. Mitri J, Muraru MD, Pittas AG. Vitamin D and type 2 diabetes: A systematic review. Eur J Clin Nutr 2011;65:1005-15.

4. Harinarayan CV. Vitamin D and diabetes mellitus. Hormones (Athens) 2014;13:163-81.

5. Issa CM, Zantout MS, Azar ST. Vitamin D replacement and type 2 diabetes mellitus. Curr Diabetes Rev 2015;11:7-16.

6. Seshiah V, Balaji V, Balaji MS, Paneerselvam A, Arthi T, Thamizharasi $\mathrm{M}$, et al. Prevalence of gestational diabetes mellitus in South India (Tamil Nadu) — a community based study. J Assoc Physicians India 2008;56:329-33.

7. Krishnaveni GV, Hill JC, Veena SR, Geetha S, Jayakumar MN Karat CL, et al. Gestational diabetes and the incidence of diabetes in the 5 years following the index pregnancy in South Indian women. Diabetes Res Clin Pract 2007;78:398-404.

8. Joergensen JS, Lamont RF, Torloni MR. Vitamin D and gestational diabetes: An update. Curr Opin Clin Nutr Metab Care 2014; 17:360-7.

9. Lacroix M, Battista MC, Doyon M, Houde G, Ménard J, Ardilouze $\mathrm{JL}$, et al. Lower vitamin $\mathrm{D}$ levels at first trimester are associated with higher risk of developing gestational diabetes mellitus. Acta Diabetol 2014;51:609-16.

10. Sablok A, Batra A, Thariani K, Batra A, Bharti R, Aggarwal AR, et al. Supplementation of vitamin $D$ in pregnancy and its correlation with feto-maternal outcome. Clin Endocrinol (Oxf) 2015.

11. American Diabetes Association. Standards of medical care in diabetes - 2014. Diabetes Care 2014;37:S14-80.

12. Holick MF, Binkley NC, Bischoff-Ferrari HA, Gordon CM, Hanley DA, Heaney RP, et al., Endocrine Society. Evaluation, treatment, and prevention of vitamin D deficiency: An Endocrine Society clinical practice guideline. J Clin Endocrinol Metab 2011; 96:1911-30.

13. Heaney RP, Holick MF. Why the IOM recommendations for vitamin D are deficient. J Bone Miner Res 2011;26:455-7.

14. G R, Gupta A. Vitamin D deficiency in India: Prevalence, causalities and interventions. Nutrients 2014;6:729-75. 
15. Fraser DR. Vitamin D-deficiency in Asia. J Steroid Biochem Mol Biol 2004;89-90:491-5.

16. Farrant HJ, Krishnaveni GV, Hill JC, Boucher BJ, Fisher DJ, Noonan $\mathrm{K}$, et al. Vitamin D insufficiency is common in Indian mothers but is not associated with gestational diabetes or variation in newborn size. Eur J Clin Nutr 2009;63:646-52.

17. Burris $\mathrm{HH}$, Camargo $\mathrm{CA}$ Jr. Vitamin $\mathrm{D}$ and gestational diabetes mellitus. Curr Diab Rep 2014;14:451.

18. Kaushal M, Magon N. Vitamin D in pregnancy: A metabolic outlook. Indian J Endocrinol Metab 2013;17:76-82.
19. Poel YH, Hummel P, Lips P, Stam F, van der Ploeg T, Simsek S. Vitamin $D$ and gestational diabetes: A systematic review and meta-analysis. Eur J Intern Med 2012;23:465-9.

20. Parlak M, Kalay S, Kalay Z, Kirecci A, Guney O, Koklu E. Severe vitamin $D$ deficiency among pregnant women and their newborns in Turkey. J Matern Fetal Neonatal Med 2014;30:1-4.

21. Soheilykhah S, Mojibian M, Moghadam MJ, Shojaoddiny-Ardekani A. The effect of different doses of vitamin $D$ supplementation on insulin resistance during pregnancy. Gynecol Endocrinol 2013;29:396-9. 